\title{
Putting the "Comprehensive" in Comprehensive Sexuality Education: a Review Exploring Young Adult Literature as a School-based Intervention
}

\author{
Margaret M. Palmer ${ }^{1}$ D . Jennifer S. Hirsch²
}

Accepted: 9 February 2022 / Published online: 18 February 2022

(c) The Author(s), under exclusive licence to Springer Science+Business Media, LLC, part of Springer Nature 2022

\begin{abstract}
Introduction In this article, we review research on the impact of young adult literature (YAL) on young people's sexualityrelated beliefs. This research points to the potential of YAL as a tool through which schools can offer sex education that is truly "comprehensive" by providing young people an opportunity to grapple with questions about gender, sexuality, and healthy relationships in literature classes, and to complement CSE in health education classes. This broader approach addresses a potential limitation of school-based comprehensive sex education (CSE). CSE certainly promotes young people's health and well-being, but an emphasis on biological dimensions of sexual and reproductive health to the exclusion of social factors, or insufficient time to address social dimensions of sexual and reproductive health, can fail to amplify or even undermine CSE messages about healthy relationships and sexuality.

Methods This scoping review examined research on YAL dealing with dating and relationships, gender role development, LGBTQ life, sexuality, sexual behaviors, and sexual health outcomes in Communications Abstracts, ERIC, MEDLINE, MLA International Bibliography, and PsycINFO databases. The search, run in December 2020, returned 265 articles, of which 18 were empirical studies of YAL and sexuality that met inclusion criteria for the review. Each included study was examined to identify the books' impacts and the methodological approach to assessing those impacts.

Conclusions Existing research suggests that YAL in the classroom can affect discourses on masculinity, femininity, violence, sexual health, and LGBTQ life. Bringing YAL into different classroom settings has the potential to be a powerful force in integrated CSE.

Policy Implications Using YAL in a variety of classroom settings, including but not limited to health and English Language Arts, will strengthen the comprehensive aspects of CSE.
\end{abstract}

Keywords Adolescent $\cdot$ Comprehensive sexuality education $\cdot$ Gender $\cdot$ School $\cdot$ Sexual script $\cdot$ Sexuality $\cdot$ Young adult literature

\section{Introduction}

Adolescence is a time of intense social development for young people as they increasingly rely on peers over parents, begin to explore sexual and romantic relationships, and set

Margaret M. Palmer

mmp09@email.unc.edu

1 Department of Sociology, University of North CarolinaChapel Hill, 155 Pauli Murray Hall, UNC-CH, Chapel Hill, NC 27599, USA

2 Department of Sociomedical Sciences, Columbia University Mailman School of Public Health, 722 West 168th Street, 5th Floor, New York, NY 10032, USA behavioral patterns for their lives (Patton et al., 2016). Comprehensive health education (CHE) covers a variety of biosocial health topics, including drugs and alcohol, mental and emotional health, physical health such as diet and physical activity, safety and violence, and sexual health (CDC, 2021a, b). However, school health programs and sex education curricula frequently emphasize biological dimensions of sexual and reproductive health, even under a CHE framework. For example, the Centers for Disease Control and Prevention (CDC) website states that sexual health education should "help prevent HIV, STDs, and unintended pregnancy among adolescents" (CDC, 2020). This focus on health outcomes relegates sexuality and sex to something with three dangerous outcomes: an STI, HIV, or pregnancy. 
As part of CHE, however, comprehensive sexuality education (CSE) is a curricular approach to this specific domain of CHE that extends beyond prevention HIV, other STIs, or pregnancy, to cover a broad range of sexuality topics, providing medically accurate information and critical thinking skills (Sex Education Collaborative, 2018; NSES, 2020). The National Sexuality Education Standards for CSE covers seven topic areas: Healthy Relationships, Anatomy and Physiology, Puberty and Adolescent Sexual Development, Gender Identity and Expression, Sexual Orientation and Identity, Sexual Health, and Interpersonal Violence (NSES, 2020). These seven topics can help address the gaps left behind when schools focus on an exclusively biological approach to sex education. Thirty years of research supports the use of CSE, finding that CSE reduces homophobia and homophobic bullying, increases understanding and appreciation of sexual and gender diversity, and improves knowledge about and decreases instances of intimate partner and domestic violence, among other social justice and health outcomes (Goldfarb \& Lieberman, 2021). Changes in CSE need to also include teachers: when teachers are unaware of their biases or actively harass or joke about students, they can perpetuate inequalities in ways that cause harm to students (Fields, 2008; Pascoe, 2011).

Taking sex education out of the exclusive domain of the health classroom and putting the "comprehensive" in comprehensive sexuality education requires amplifying content delivered in health classes by integrating sexuality education into other areas of the curriculum. Such approaches to social justice education, relying on critical literacy in education, have been effective in challenging gender inequity and stereotypes (Goldfarb \& Lieberman, 2021). Based on Social Learning Theory and Social Cognitive Theory, the NSES employ the idea that students need to be able to see themselves in the material, seeing their education as relevant to themselves, and that CSE should help students change their perceptions of what is "normal" (NSES, 2020). Bringing age-appropriate outside sources into literature/English classes can complement the sexuality education received in health classes, providing additional opportunities for young people to engage with these vital questions about identity, relationships, and the social world. Bringing CSE into nonhealth classes can also open opportunities for teachers to collaborate across disciplines and CSE goals.

One way to do that is to bring young adult literature (YAL) into the English and Language Arts classrooms and use it to teach a variety of skills, including understanding of and inclusive practices around sexuality, gender identity and sexual orientation, and sex behaviors. Research suggests that YAL can promote critical thinking across topics, though research looking at outcomes of doing so continues to be limited. This speaks to questions raised by Critical Literacy Theory, which examines how popular media uses language and symbols that promote an unquestioning acceptance of social and political inequality, and argues for the idea of "critical literacy," which involves the capacity to think critically about the messages conveyed by media (Behrman, 2006). Research into CSE shows that using literature is beneficial to the goals of CSE and that critical literacy approaches to media in particular are effective tools for expanding how adolescents engage with gender and gender norms (Goldfarb \& Lieberman, 2021). Research also suggests that YAL can be leveraged in classroom settings for other socially oriented goals (for examples, see de Leon, 2017; Ellis, 2021; Hayn et al., 2016; Hughes \& Laffier, 2016; Oldham, 2019). Because research suggests uses of YAL in the classroom but without a clear understanding of leveraging YAL to contribute to CSE, the current study identifies and reviews empirical studies that look at YAL as a method of learning about CSE-related topics.

This study uses a scoping review framework (Sucharew \& Macaluso, 2019) to critically examine the existing research in communication, education, psychology, public health, and medical research concerned with YAL in relation to topics covered in CSE. Although geared at understanding the role YAL could play in schools, both within and beyond health classrooms, this study includes research on YAL conducted in a variety of contexts in order to fully synthesize existing research on how YAL has been utilized. After describing the 18 empirical studies' designs and findings, the study examines those articles that used YAL as an intervention for educators or adolescents. Finally, by identifying what research exists on YAL and CSE, the potential of leveraging YAL in the classroom as a part of CSE is highlighted and discussed.

\section{Methods}

As a scoping review, the primary goal of this study was not to answer a particular question but rather to identify research that examined YAL and CSE. In December 2020, searches were run through five databases: Communications Abstracts, ERIC, MEDLINE, MLA, and PsycINFO. In these databases, search terms "sexual* OR sex OR dating OR 'romantic relationship"” were crossed with " "young adult literature' OR 'YA literature' OR 'young adult fiction' OR 'YA fiction' OR 'young adult novels' OR 'YA novels' OR 'adolescent literature' OR 'adolescent fiction' OR 'adolescent novels'." This set of search returned 265 entries published from 1990 to 2019, in English, and as part of academic journals, dissertations, or books.

Scoping review inclusion criteria for articles or chapters were (1) empirical research (rather than content analysis); (2) examination of YAL, defined as novels written for an audience between 12 and 20 years of age, and (3) discussion of impact on sexual and romantic identities, practices, or 
beliefs. The results of the search and exclusions are depicted in Fig. 1. First, any studies that used the terms "literature" and "young adult" to denote a literature review of research about young adults were removed $(n=6)$. Of the remaining 259 items identified, 18 studies were removed for being about media other than YAL and 11 were removed for being about a topic not about media exposure at all. An additional 39 studies were removed because they were activist or op-ed articles, editorials, guides, interviews, or other non-empirical articles. Finally, 173 articles were removed because they were content analyses; since the goal of this scoping review is to uncover research explicitly about the impacts of YAL as an intervention, these content analyses were removed from consideration.

The remaining 18 articles presented empirical research on YAL's impacts on readers. The research designs of these articles are first examined; although a school-based intervention using YAL is a primary interest of this review, research relying on other learning contexts and teaching methods were included in the review. Each of the 18 articles' outcomes was then analyzed in comparison to the seven topic areas of NSES, as was done in Goldfarb \& Lieberman (2021). After examining the different dimensions of CSE examined in each article, the six studies that used YAL explicitly as an intervention, four of
Fig. 1 Flow diagram of exclusions

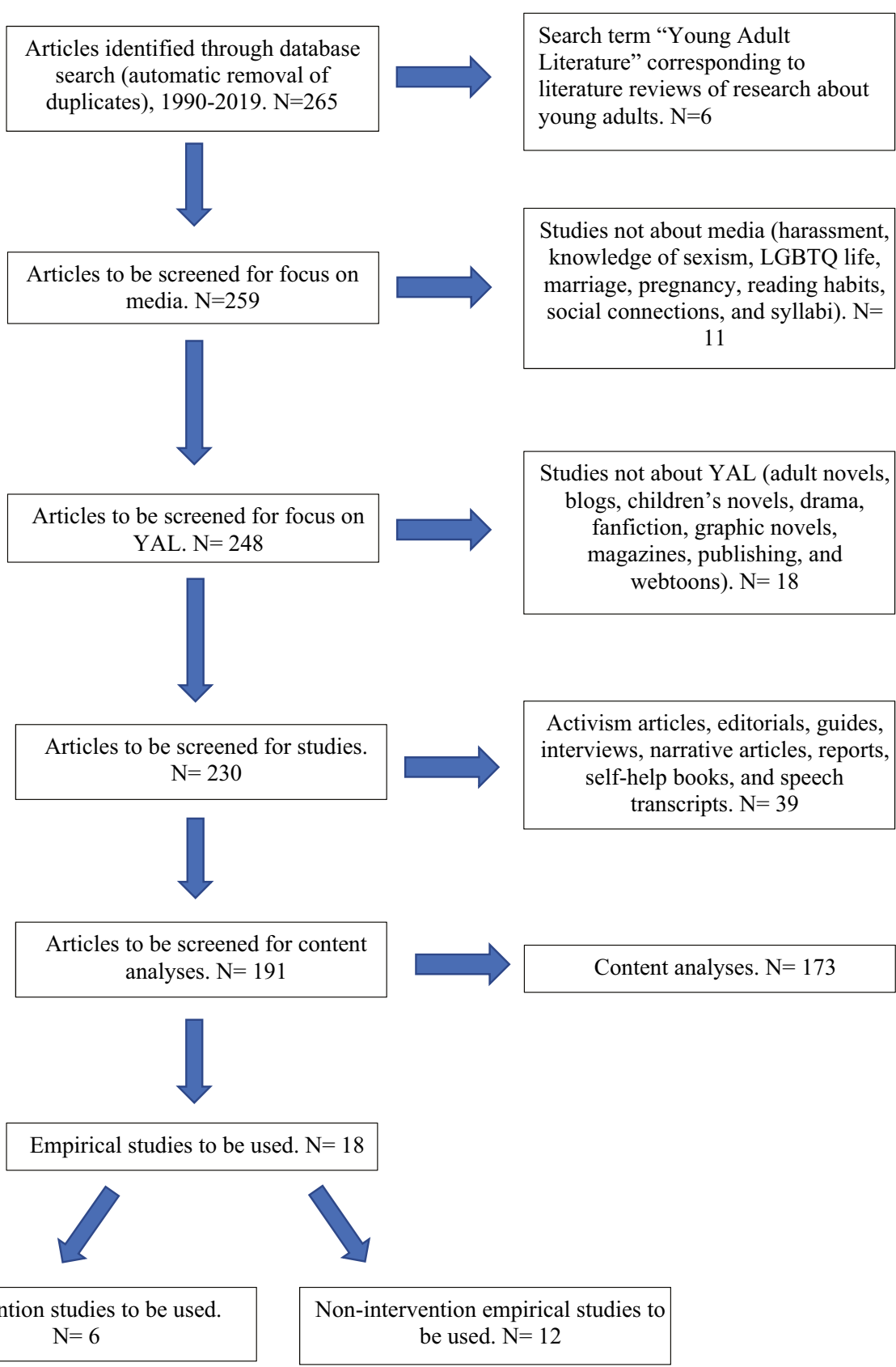


which examine the impact of YAL on young people and two of which examine the impact on teachers, are discussed further.

\section{Results}

The studies included in this review examine YAL's impact on empathy and inclusion, identity, sexual practices and beliefs, and violence. There were two distinct types of research conducted: those that were observational, dedicated primarily to retrospective or class work analysis, and those that explicitly leveraged YAL as an intervention in the classroom. Of the 18 articles included, 12 were observational or retrospective and six used YAL as an intervention. Table 1 lists each article, including noting (in the fifth column) which of the corresponding 2020 NSES topics it addresses. After reviewing the range of research designs, all 18 studies are discussed, organized by which NSES topic they address. After the broader analysis, the six studies that used YAL as an intervention in the classroom are discussed in more detail, including the choices to use different classroom types and use of adolescents versus preservice teachers (PSTs) as subjects.

\section{Research Design}

Research methods ranged widely, including surveys, interviews, discussion board analyses, and participant observation. Many studies lacked strong research designs, with potential limitations due to small sample size and recall bias. Because of the emphasis on teaching and classroom impacts of YAL, using courses and coursework as data was a common approach. Courses and course units that dealt with YAL for adolescents (Brozo et al., 2002; Hsieh, 2012; Malo-Juvera, 2013; Schieble, 2010; Sprague \& Risher, 2002; Young, 2000) provided ways to study the impacts of engaging with YAL. Qualitative research included analyses of papers and discussion board posts to see how students felt about the assigned YAL (Hsieh, 2012; Schieble, 2010; Sprague \& Risher, 2002; Young, 2000), though the graded aspect of these courses may have impacted the data sources. Pre- and post-testing (Brozo et al., 2002; Malo-Juvera, 2013) or follow-up interviews (Sprague \& Risher, 2002; Young, 2000) were also used. Classroom-based methodologies were also used for the studies that examined YAL and PSTs (Batchelor et al., 2018; Beck et al., 2017; Brendler, 2014; Parsons, 2016).

Participant observation and ethnographic methods (Batchelor et al., 2018; Blackburn \& Clark, 2011; Godina \& Soto-Ramirez, 2017) in classrooms and book clubs provided rich detail about YAL and gender relations, sexual identities, and development over time. Interviews (Mariani-Petroze, 2006; Sciurba, 2014; Sprague \& Risher, 2002; Young, 2000) also allowed participants to dig into their own perspectives and experiences, providing rich data that can inform future research in this area. However, the sample sizes for research using ethnographic methods or participant observation were very small - some as few as four participants (Young, 2000).

Some research used cross-sectional surveys (BowlesReyer, 1998; Mariani-Petroze, 2006; Schultheis, 1990) to collect information about what participants recall of their own reading and their subsequent reflections. However, the limitations of such cross-sectional surveys, including recall bias, might make cross-sectional surveys a weaker design for future research. Recall bias also potentially was a problem for Aronian (2015), in which the data was the researcher's own recalled memories of reading YAL.

\section{Psychosexual and Gender Development Impacts of Exposure to YAL}

Because many papers had outcomes that could fall into more than one category, mutual exclusivity is not possible. Thus, we examine the research by grouping papers into broad categories based on the outcomes discussed in each paper were chosen-for instance, a study about increasing empathy for trans* students was broadly part of the "Sexual Orientation and Identity" category but also fell into the category of sexual health or gender identity. Overall, four primary NSES topics dominated the current research: Sexual Orientation and Identity, Interpersonal Violence, Gender Identity and Expression, and Sexual Health. Figure 2 shows the breakdown of NSES topics covered by the different articles; because some articles are listed in more than one topic, the totals presented in the chart exceed the total number of articles.

\section{Sexual Orientation and Identity}

Nine of the articles examined YAL's potential to build or increase empathy readers' empathy for LGBTQ students and across the gender binary, particularly increasing boys' engagement with gender diversity.

Four of the five articles on sexual orientation and identity relied on preservice teachers rather than or in addition to adolescents, suggesting that a primary goal is how to build empathy among teachers (Batchelor et al., 2018; Beck et al., 2017; Parsons, 2016; Schieble, 2010). This work is grounded in the assumption that expositing teachers to LGBTQ-oriented YAL through training will make them more supportive of LGBTQ students and more likely to bring LGBTQ-oriented books into the classroom; Batchelor et al. (2018), Beck et al. (2017), Parsons (2016), and Schieble (2010) found that reading YAL featuring LGBTQ novels increased feelings of connectedness to and empathy for the characters. These readerto-character empathetic feelings may translate outside of the 


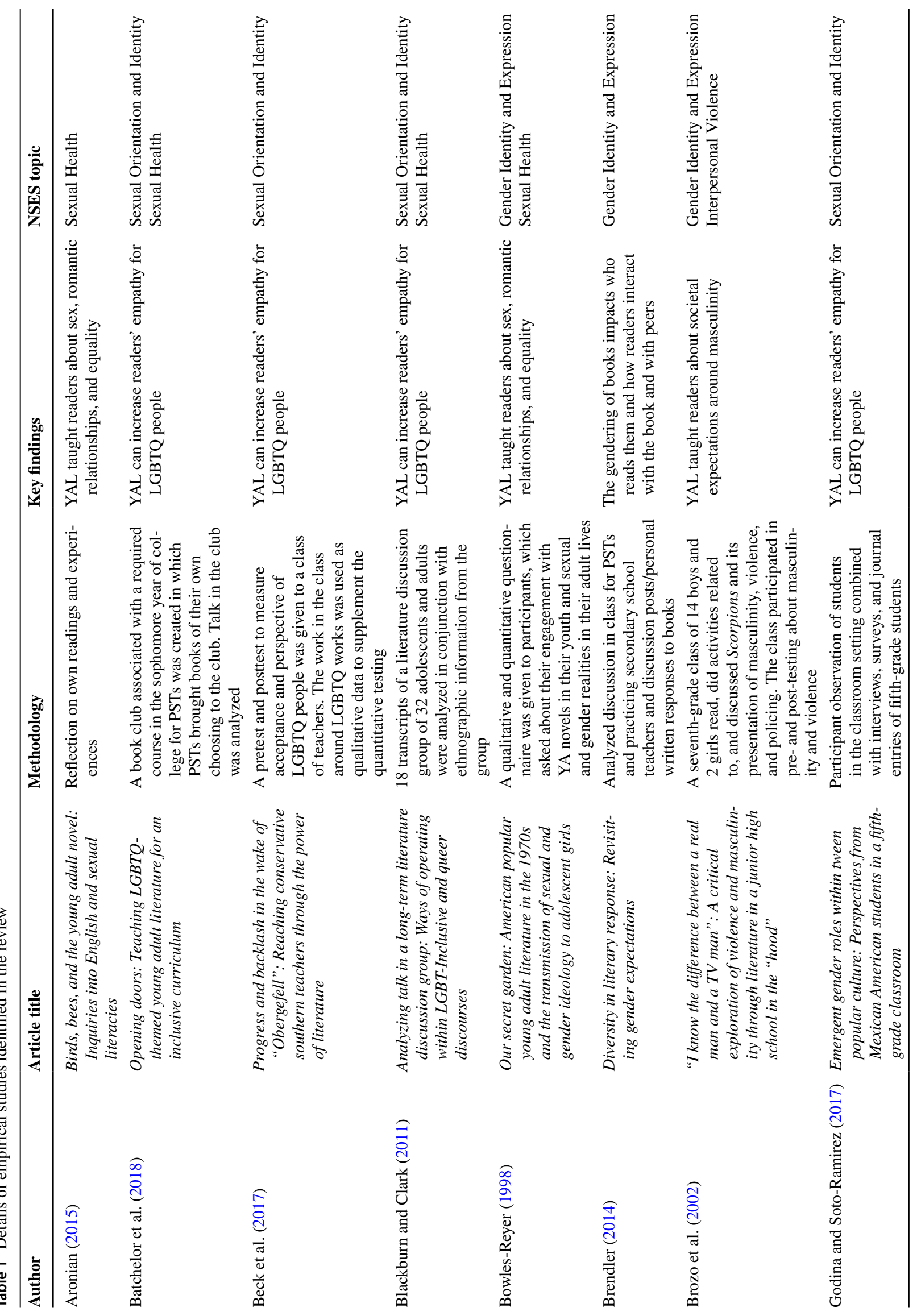




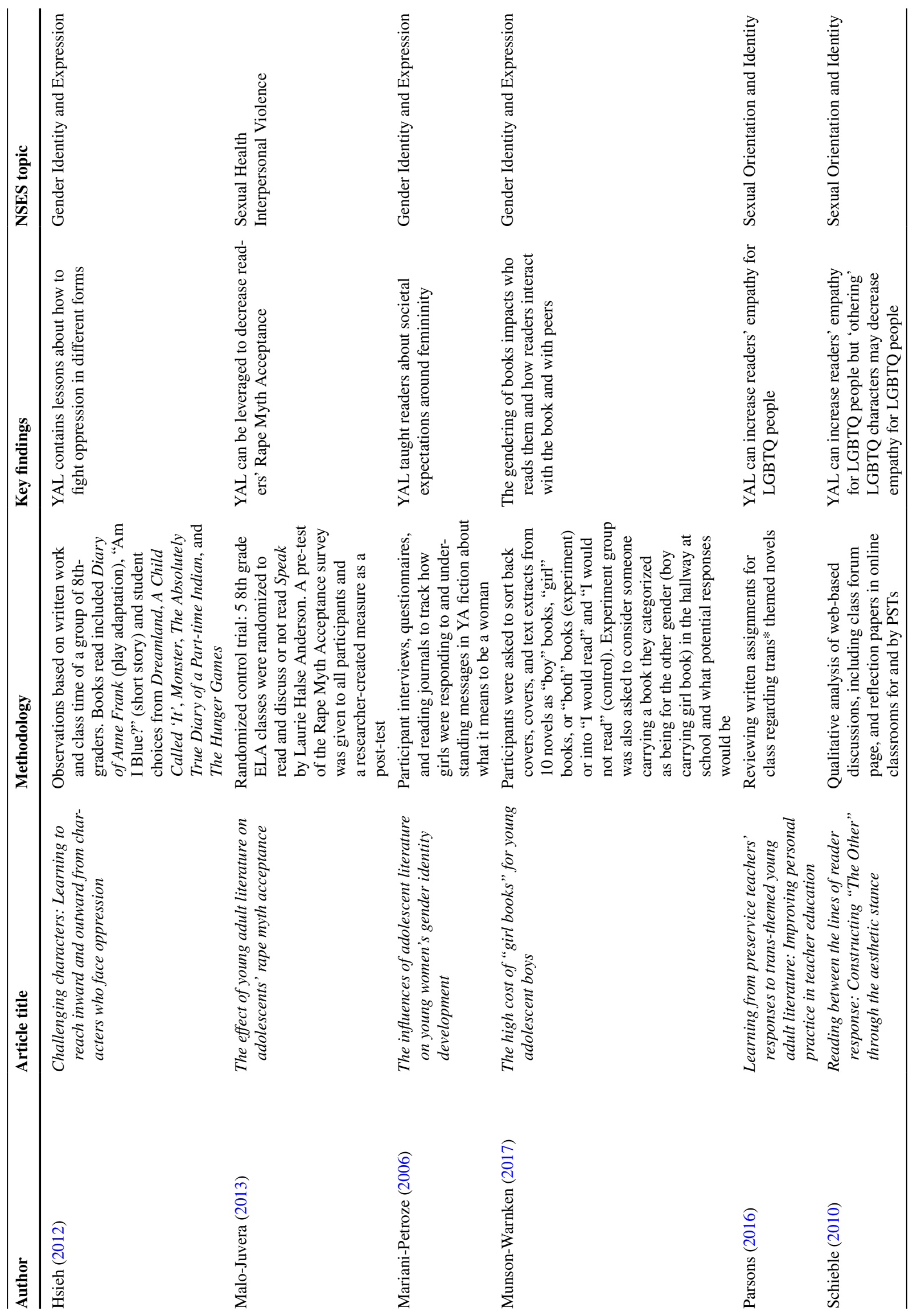




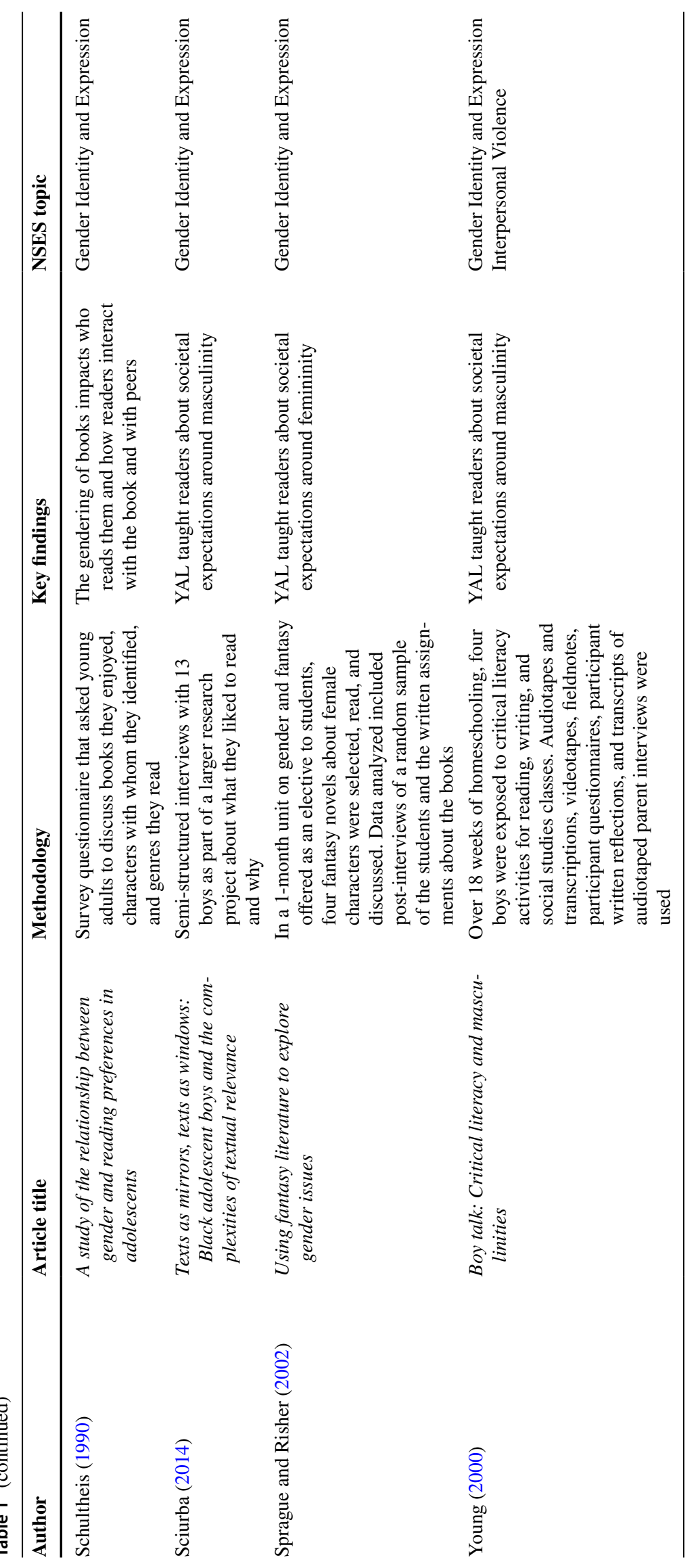


Fig. 2 NSES topics as focus of reviewed articles

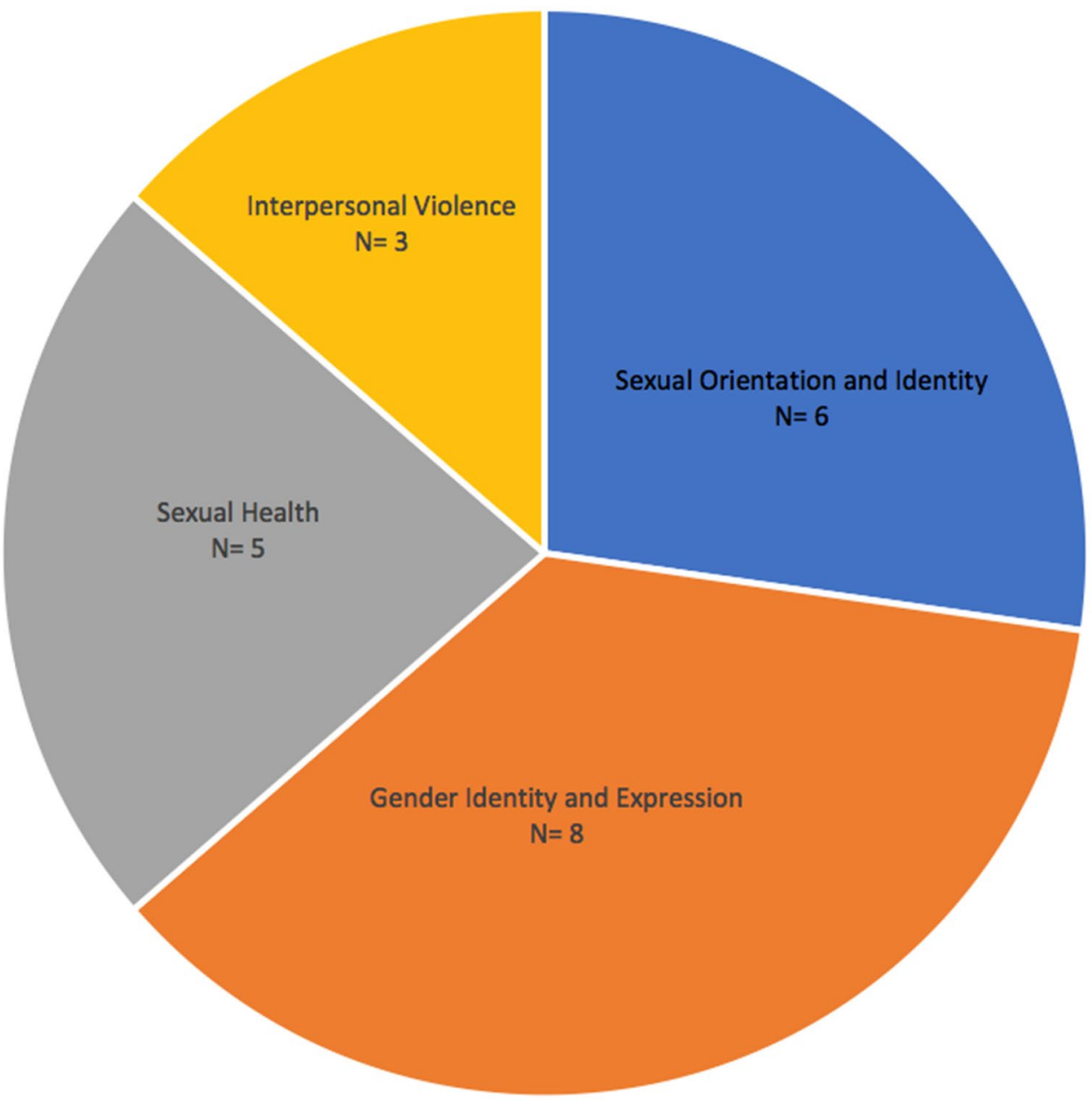

reader-character world and increase feelings of empathy for sexual and gender minorities.

For adolescent readers of YAL, research has shown that reading and discussing books engendered empathy for LGBTQ characters (Blackburn \& Clark, 2011; Godina \& Soto-Ramirez, 2017; Sprague \& Risher, 2002), although research has also shown that the character telling the story does have the ability to reinforce the "Otherness" of LGBTQ characters, which may decrease empathy for LGBTQ people (Schieble, 2010).

\section{Interpersonal Violence}

The three articles analyzed that dealt with YAL and violence suggest that gender scripts in YAL may shape young people's attitudes towards violence, either by promoting it or deterring it. Violence is often masculinized in YAL, presenting physical prowess and force as something needed by boys to become men (Brozo et al., 2002; Young, 2000). Though these messages reinforce violence as part of ideal masculinity, critical in-class discussions of these texts can also provide opportunities to discuss why physical violence (Brozo et al., 2002; Young, 2000) and sexual violence (Malo-Juvera, 2013) are not necessary for becoming "real men" and how that masculine ideal can be harmful. Learning to read YAL critically allowed adolescents to begin to identify the role of violent masculinity in the books and in their own lives (Brozo et al., 2002; Young, 2000). Critical literacy activities engage with gender using books in the classroom to shift perspectives and challenge hegemonic discourses, including those of Whiteness and masculinity (Young, 2000). MaloJuvera (2013) found that reading and discussing with Laurie Halse Anderson's novel about surviving rape, Speak (Anderson, 1999), significantly impacted 8th grade boys' Rape Myth Acceptance suggesting that shifting the conversation around sexual violence in the classroom could have long-lasting impacts as adolescents begin to navigate the world.

\section{Gender Identity and Expression}

Some of the articles about developing one's identity also examined the impact on empathy, in part because building empathy may include empathy for one's self. Eight articles 
examined how YAL impacts the readers' gender and gendered identities.

For adolescent girls, books that followed female characters helped them to engage with the pressures placed on them while growing up (Sprague \& Risher, 2002). One study found that girls generally felt that they could filter out unwanted messages about femininity (Mariani-Petroze, 2006), but others suggested that the different versions of femininity presented in novels may impact their own gender and sexual identities (Bowles-Reyer, 1998; Mariani-Petroze, 2006; Sprague \& Risher, 2002). Because girls gravitate towards books with romantic subplots (Schultheis, 1990), a pattern that reemerged during the Twilight (Meyer, 2005) era, it is important to engage with these materials in classroom discussions (Sprague \& Risher) so that YAL can be read critically and discussed.

For adolescent boys, adventure books provided malecentered novels that explored masculinity and growing up (Brendler, 2014; Schultheis, 1990). The mirror offered to readers by YAL proved especially important for Black boys (Sciurba, 2014). Books following Black male characters, which might reflect the experiences, identities, and/or issues grappled with by Black boys, helped readers see other versions of masculinity than hegemonic masculinity (Sciurba, 2014).

Using YAL in the classroom to explicitly challenge stereotypes was also shown to increase empathy among adolescents (Godina \& Soto-Ramirez, 2017). Fantasy YAL was a powerful way to explore unequal gender relationships and to expose boys to more positive representations of femininity (Sprague \& Risher, 2002). Because YAL is typically separated into "boy books" and "girl books," with distinct messages marketed to different genders, researchers found it was important to expose adolescents to books from across the spectrum (Brendler, 2014; Godina \& Soto-Ramirez, 2017; Munson-Warnken, 2017). YAL can also be used to explicitly teach ways of engaging with and fighting against oppression in different forms (Hsieh, 2012).

\section{Sexual Health}

Five articles showed that reading YAL has direct and measurable impacts on sexual literacy, practices, and violence. Additionally, as discussed above, YAL has been shown to shift adolescent boys' Rape Myth Acceptance scores (MaloJuvera, 2013). Relatedly, another study found that reading sex-positive YAL, such as Judy Bloom's coming of age story Forever, increased girls' self-esteem and egalitarian relationship-seeking behaviors (Bowles-Reyer, 1998). Sexpositive YAL has also been shown to help students grapple with their own sexual identities (Aronian, 2015) and desires (Aronian, 2015; Bowles-Reyer, 1998). Research provides evidence that LGBTQ-centered YAL helped readers explore their own sexual identities (Batchelor et al., 2018; Blackburn \& Clark, 2011). Retrospective research shows how the sexual scripts provided by YAL echo into adulthood, leading to different sexual and relationship outcomes than might have otherwise been had (Aronian, 2015; Bowles-Reyer, 1998).

\section{YAL as Intervention}

Of the 18 research studies discussed above, six evaluated the impact of YAL as a classroom intervention. Of these six, two examined the impact of YAL in teachers' perspectives on and inclusion of certain YAL in the classroom. The other four used YAL as a curricular element, with pre- and post-testing or interviews to measure the impacts on adolescent students. Table 2 shows the outcome of focus for each study, including the number of subjects (when available), the classroom type, and the topic focused on by researchers.

Research on PSTs and educators examined the use of LGBTQ YAL as an intervention for both teachers and for their future students. Using YAL in educator classrooms shows that exposure to LGBTQ novels impacts teachersin-training perspectives on the importance of including LGBTQ literature and voices in the classroom (Beck et al., 2017; Parsons, 2016). Each experiment used a PST classroom in which reading LGBTQ YAL was required. Parsons (2016) relied on examining written assignments for the PSTs to detect increased empathy for trans* characters. Beck et al. (2017) used a measure of acceptance of and perspectives on LGBTQ people as a pre- and post-test before a unit that required LGBTQ YAL. Both found that LGBTQ YAL increases feelings of empathy and support for LGBTQ youth.

The four interventions that targeted adolescents used varied methods to bring YAL into classroom settings. Young (2000) used YAL in critical literacy lessons during a homeschool experiment involving her two sons and two other boys. This small, focused, and homogenous classroom setting placed the researcher/educator in a position that increased the risk of socially desirable responses by the class participants. However, the outcome of the class

Table 2 Outcome assessed in intervention studies identified in the review

\begin{tabular}{|c|c|c|c|}
\hline Article & $N$ & Classroom type & Intervention topic \\
\hline Beck et al. (2017) & 17 & Preservice Teachers & LGBTQ Inclusivity \\
\hline Parsons (2016) & 32 & Preservice Teachers & LGBTQ Inclusivity \\
\hline Young (2000) & 4 & Homeschool & Masculinity \\
\hline Brozo et al. (2002) & 16 & Elective Course & Masculinity \\
\hline $\begin{array}{l}\text { Sprague et al. } \\
\text { (2002) }\end{array}$ & & Elective Course & Femininity \\
\hline Malo-Juvera (2013) & 139 & General Class & $\begin{array}{l}\text { Rape Myth Accept- } \\
\text { ance }\end{array}$ \\
\hline
\end{tabular}


was that the four boys had been able to reframe representations of masculinity as associated with strength, bravery, and superiority to women (Young, 2000).

Two of the interventions used YAL in elective courses in traditional classrooms. These classes, one on fantasy novels that center female voices (Sprague \& Risher, 2002) and the other on masculinity (Brozo et al., 2002), were both elective courses, potentially clouding some of the impact of YAL. Pre- and post-testing (Brozo et al., 2002) or post-interviews (Sprague \& Risher, 2002) showed that using YAL in elective courses impacts gender perspectives. Students in the femalecentered fantasy course discussed social expectations for women, including a romance script that was seen as controlling female characters' agency (Sprague \& Risher, 2002). Students in the "Real Men" course understood different ways of being a "real man" and that masculinity and violence had been previously, but did not need to be, linked (Brozo et al., 2002).

Only one intervention used exposure to a single piece of YAL as a treatment in a randomized control trial (MaloJuvera, 2013). Seven 8th-grade English/Language Arts classes were randomized to either read and discuss or not read Speak by Laurie Halse Anderson (1999). Students in each class were given a pre-test that included the Rape Myth Acceptance scale and a researcher-developed scale, the Adolescent Date Rape Scale. The quasi-experimental design showed that reading Speak significantly impacted adolescents' acceptance of the "she wanted it" rape myth, including that there was no backlash by high rape myth accepting students, particularly for boys (Malo-Juvera, 2013).

\section{Limitations}

This review has some important limitations. First, we drew on only five databases: Communications Abstracts, ERIC, MEDLINE, MLA International Bibliography, and PsycINFO. These databases were chosen in order to explore the role of YAL in health, development, and education. It is possible that more empirical research exist outside these databases. In order to minimize this limitation, broad searches were used. This meant that many articles in the search had to be removed because limiting the search terms risked missing research in these databases. Secondly, the preponderance of scholarship on YAL is content analyses, which were removed from consideration. This choice was made to emphasize what empirical studies exist but it also excludes a great deal of scholarship on YAL. Finally, the diverse methods, sample sizes, and research subjects utilized limited the comparisons that could be made. The vast differences in studies' methods, samples, and rigor made direct quality comparison difficult.

\section{Summary and Discussion}

In summary, there is research on using YAL as an intervention in four areas aligned with the national standards for sex education: sexual orientation and identity, interpersonal violence, gender identity and expression, and sexual health (NSES, 2020). Despite limitations in research design, this work shows that reading YAL in classrooms, book clubs, and for pleasure influenced the ways in which readers perceived others and themselves. YAL about LGBTQ characters increased feelings of empathy for LGBTQ people. YAL helped boys separate and identify messages about masculinity, strength, violence, and power over women. It helped teach girls about the romantic scripts provided in books and to ask for equitable relationships with men. Most of this research was observational, with a small number of studies that used YAL as interventions, although only one study used YAL with an RCT study design. Overall, YAL engages with many dimensions of adolescent psychosexual and gender development.

Although the body of research identified is still quite small, it points to the potential of YAL as an important part of CSE. This scoping review raises many questions to be answered by subsequent research. This would include research that uses more rigorous study designs, examines the impact of using YAL as a tool for teacher training on the actual classroom environment, and accounts for differences in social and political context which may affect the adoption of YAL about gender and sexuality. Sexuality educators increasingly recognize the importance of addressing intersectional inequalities, and so further research on the use of YAL to help make comprehensive sexuality education truly comprehensive should examine the impact on gender and sexuality in combination with the impact on ideas about racism, disability, and other forms of social inequality.

The intensive homeschooling model used by Young (2000) offers great flexibility for curriculum, but only approximately $3.3 \%$ of children in the USA are homeschooled, though this number spiked to $11.1 \%$ during the COVID-19 pandemic (Eggleston \& Fields, 2021). The elective model has the potential to reach more school-aged children, but electives still depend on student interest to opt-in to the elective class before being exposed to the YAL and subsequent discussions about gender and sexuality, and may reach the students who are already most critically engaged with those topics. Though only one study used it in this way, integrating sexuality education into required classes like English/Language Arts shows potential to complement the delivery of content in specially designated "sexuality education" classes so that schools can 
offer integrated, comprehensive sexuality education curriculum. That students do not opt-in for English courses will also increase the reach of the curriculum rather than keeping such courses as electives.

Although this review emphasized sex and sexuality, some of the articles hint at a broader applicability of YAL in the classroom. Hsieh (2012) focused on using YAL to teach about oppression and resistance writ large, including teaching about the Holocaust. Sciurba (2014) examined the role YAL can take in teaching about the intersections of race and gender, looking particularly at the experiences of Black boys. New YAL that tells stories rooted in the search for social justice, such as award-winning books The Hate U Give (Thomas, 2017) and Children of Blood and Bone (Adeyemi, 2018), could also be incorporated into other classes to discuss the intersections of race, gender, and sexuality. NSES's, (2020) standards emphasize intersectionality and social justice as part of the mission of CSE, making the use of YAL on a variety of topics and from different genres a good match for CSE's topics and skill development goals. Using YAL as part of CSE can bridge the boundaries between sexual health classes and the rest of students' lives.

\section{Conclusion}

Bringing comprehensive and intentional discussions about sex and sexuality into classes beyond health education has the potential to nurture students' sense of self, feelings of empathy for others, and ability to engage in healthy relationships. Vitally, the empirical studies reviewed in this article all suggest that YAL has an impact on adolescents. A crucial next step, beyond exploring further realms of research, is to identify strategies to encourage district-level adoption of this more comprehensive approach to comprehensive sexuality education. Approximately $40 \%$ of school districts have already adopted NSES (CDC, 2016) and educator training courses can be effective ways to share information about bringing YAL into the classroom (Beck et al., 2017; Parsons, 2016). YAL is an important pedagogical tool for educators working to bring their curricula in line with NSES. Additionally, this review brings to light important information for policymakers, CSE advocates, school boards, and departments of education. For change to CSE to be comprehensive, decision-makers at each level should consider the potential for using YAL as an intervention in schools. Efforts to fully integrate aspects of CSE into more classrooms may engender less pushback than stand-alone CSE often faces in some districts.

Overall, this review suggests that, while more research is needed, there is potential to use YAL in classrooms to incorporate messages about masculinity and femininity, LGBTQ people, and sexual and romantic relationships into varied classroom settings. Integrating topics from the National Sexuality Education Standards across the curriculum is a promising strategy to provide young people with CSE that is truly comprehensive.

Funding Jennifer Hirsch's contributions to this publication were supported by the Eunice Kennedy Shriver National Institute of Child Health and Human Development under grant number P2CHD058486, awarded to the Columbia Population Research Center. The content is solely the responsibility of the authors and does not necessarily represent the official views of the National Institutes of Health.

Availability of Data and Materials Not applicable.

Code Availability Not applicable.

\section{Declarations}

Conflict of Interest The authors declare no competing interests.

\section{References}

Adeyemi, T. (2018). Children of blood and bone. Henry Holt and Co. Anderson, L. H. (1999). Speak. Farrar Straus Giroux.

Aronian, K. R. (2015). Birds, bees, and the young adult novel: Inquiries into English and sexual literacies [EdD]. Columbia University.

Batchelor, K. E., Ramos, M., \& Neiswander, S. (2018). Opening doors: Teaching LGBTQ-themed young adult literature for an inclusive curriculum. The Clearing House, 91(1), 29-36.

Beck, S. A., Walker-DeVose, D., Agnich, L. E., Town, C., \& Smith, T. (2017). Progress and backlash in the wake of Obergefell: Reaching conservative southern teachers through the power of literature. American Journal of Sexuality Education, 12(2), 170-194.

Behrman, E. H. (2006). Teaching about language, power, and text: A review of classroom practices that support critical literacy. Journal of Adolescent and Adult Literacy, 49(6), 490-498.

Blackburn, M. V., \& Clark, C. T. (2011). Analyzing talk in a long-term literature discussion group: Ways of operating within LGBT inclusive and queer discourses. Reading Research Quarterly, 46(3), 22-248.

Bowles-Reyer, A. (1998). Our secret garden: American popular young adult literature in the 1970s and the transmission of sexual and gender ideology to adolescent girls [PhD, Women's Studies]. George Washington University.

Brendler, B. M. (2014). Diversity in literary response: Revisiting gender expectations. Journal of Education for Library and Information Science, 55(3), 223-240.

Brozo, W. G., Walter, P. W., \& Placker, T. (2002). "I know the difference between a real man and a TV man": A critical exploration of violence and masculinity through literature in a junior high school in the hood. Journal of Adolescent \& Adult Literacy, 45(6), $530-538$.

CDC. (2016). Results from the school health policies and practices study (School Health Policies and Practices Study, p. 104). CDC.

CDC. (2021). Health Education Curriculum Analysis Tool (HECAT): Overview (Health Education Curriculum Analysis Tool, p. 16). CDC.

CDC. (2020). What works: Sexual health education. Centers for Disease Control and Prevention. Retrieved September 27, 2021. (https:// 
www.cdc.gov/healthyyouth/whatworks/what-works-sexual-healtheducation.htm)

de Leon, C. (2017). Engaging adolescents in mental health discussions through young adult literature: A literature review. Q Space, 11, 4-13.

Eggleston, C., \& Fields, J. (2021). Homeschooling on the rise during COVID-19 pandemic: Census Bureau's Household Pulse survey shows significant increase in homeschooling rates in fall 2020. Census Bureau.

Ellis, S. E. (2021). Teachers' perceptions of using young adult literature as a catalyst to discuss social justice in Mississippi classrooms. $\mathrm{PhD}$, Philosophy. University of Mississippi.

Fields, J. (2008). Risky lessons: Sex education and social inequality. Rutgers University Press.

Godina, H., \& Soto-Ramirez, C. (2017). Emergent gender roles within tween popular culture: Perspectives from Mexican American students in a fifth-grade classroom. Journal of Latinos and Education, 16(2), 98-109.

Goldfarb, E. S., \& Lieberman, L. D. (2021). Three decades of research: The case for comprehensive sex education. Journal of Adolescent Health, 68(1), 13-27.

Hayn, J. A., Clemmons, K. R., \& Olvey, H. A. (2016). Fostering inclusion of disabled youth through young adult literature: Action research with wonder. Study and Scrutiny: Research on Young Adult Literature, 1(2), 64-78.

Hsieh, B. (2012). Challenging characters: Learning to reach inward and outward from characters who face oppression. The English Journal, 102(1), 48-51.

Hughes, J., \& Laffier, J. L. (2016). Portrayals of bullying in young adult literature: Considerations for schools. Canadian Journal of Education, 39(3), 1-24.

Malo-Juvera, V. (2013). The effect of young adult literature on adolescents' rape myth acceptance. EdD, Curriculum and Instruction. Florida International University.

Mariani-Petroze, C. C. (2006). The influences of adolescent literature on young women's gender identity development $[\mathrm{EdD}]$. University of Kentucky.

Meyer, S. (2005). Twilight. Little, Brown, and Company.

Munson-Warnken, M. (2017). The high cost of "girl books" for young adolescent boys. The Reading Teacher, 70(5), 583-593.
NSES. (2020). National sex education standards: core content and skills, $K-12$, 2nd edition (p. 72). Future of Sex Education.

Oldham, L. E. (2019). "A hairbrush is not a gun": Narratives and counternarratives of race, power, and identity in young adult literature. $\mathrm{PhD}$, Curriculum and Instruction. New Mexico State University.

Parsons, L. T. (2016). Learning from preservice teachers' responses to trans-themed young adult literature: Improving personal practice in teacher education. Discourse: Studies in the Cultural Politics of Education, 37(6), 933-947.

Pascoe, C. J. (2011). Dude, you're a fag: Masculinity and sexuality in high school (2nd ed.). University of California.

Patton, G. C., Sawyer, S. M., Santelli, J. S., Ross, D. A., Afifi, R., Allen, N. B., Arora, M., \& Azzopardi, P. (2016). Our future: A Lancet commission on adolescent health and wellbeing. The Lancet, 387(10036), 2423-2478.

Schieble, M. B. (2010). Reading between the lines of reader response: Constructing "the other" through the aesthetic stance. Changing English, 17(4), 375-384.

Schultheis, C. (1990). A study of the relationship between gender and reading preferences in adolescents. Masters of Library Sciences. Kent State University.

Sciurba, K. (2014). Texts as mirrors, texts as windows: Black adolescent boys and the complexities of textual relevance. Journal of Adolescent \& Adult Literacy, 58(4), 308-316.

Sex Education Collaborative. (2018). Professional learning standards for sex education (pp. 1-8).

Sprague, M. M., \& Risher, L. (2002). Using fantasy literature to explore gender issues. ALAN Review, 29, 39-42.

Sucharew, H., \& Macaluso, M. (2019). Methods for research evidence synthesis: The scoping review approach. Journal of Hospital Medicine, 14(7), 416-418.

Thomas, A. (2017). The hate u give. Balzer \& Bray.

Young, J. P. (2000). Boy talk: Critical literacy and masculinity. Reading Research Quarterly, 35(3), 312-337.

Publisher's Note Springer Nature remains neutral with regard to jurisdictional claims in published maps and institutional affiliations. 